\title{
Sexual Conflict about Parental Care: The Role of Reserves
}

\author{
Zoltán Barta, ${ }^{1, *}$ Alasdair I. Houston, ${ }^{2, \dagger}$ John M. McNamara, ${ }^{1, \star}$ and Tamás Székely ${ }^{3, \$}$
}

1. Centre for Behavioural Biology, School of Mathematics, University of Bristol, University Walk, Bristol BS8 1TW, United Kingdom;

2. Centre for Behavioural Biology, School of Biological Sciences, University of Bristol, Woodland Road, Bristol BS8 1UG, United Kingdom;

3. Department of Biology and Biochemistry, University of Bath, Bath BA2 7AY, United Kingdom

Submitted February 5, 2001; Accepted November 30, 2001

Abstract: Parental care often increases the survival of offspring, but it is costly to parents. Because of this trade-off, a sexual conflict over care arises. The solution to this conflict depends on the interactions between the male and female parents, the behavior of other animals in the population, and the individual differences within a sex. We take an integrated approach and develop a state-dependent dynamic game model of parental care. The model investigates a single breeding season in which the animals can breed several times. Each parent's decision about whether to care for the brood or desert depends on its own energy reserves, its mate's reserves, and the time in the season. We develop a fully consistent solution in which the behavior of an animal is the best given the behavior of its mate and of all other animals in the population. The model predicts that females may strategically reduce their own reserves so as to "force" their mate to provide care. We investigate how the energy costs of caring and searching for a mate, values of care (how the probability of offspring survival depends on the pattern of care), and population sex ratio influence the pattern of care over the breeding season.

Keywords: sexual conflict, parental care, offspring desertion, dynamic game, reserves, body mass regulation.

Parental care is an energetically demanding behavior (Ricklefs 1974; Golet and Irons 1999; Hõrak et al. 1999),

* Corresponding author. Present address: Behavioural Ecology Research Group, Department of Evolutionary Zoology, University of Debrecen, Debrecen H-4010, Hungary; e-mail: zbarta@delfin.klte.hu.

† E-mail: a.i.houston@bristol.ac.uk.

¥ E-mail: john.mcnamara@bristol.ac.uk.

s E-mail: t.szekely@bath.ac.uk.

Am. Nat. 2002. Vol. 159, pp. 687-705. (C) 2002 by The University of Chicago. 0003-0147/2002/15906/0008\$15.00. All rights reserved. and thus, parents should have sufficient reserves to raise their young to independence. Parents in poor condition may terminate care and abandon their nest or young (Snyder et al. 1989; Olsson 1997; reviewed by Clutton-Brock 1991; Székely et al. 1996). Given that energy reserves play an important role in determining patterns of care, an evolutionary account of care should adopt a state-dependent approach (Houston et al. 1988; Houston and McNamara 1999; Clark and Mangel 2000). State-dependent models have been developed to investigate the decision of a single sex by Kelly and Kennedy (1993) and Webb et al. (in press). For instance, Kelly and Kennedy (1993) showed that female Cooper's hawks Accipiter cooperi should desert their young when their reserves fall below a critical level. In their model, however, the behavior of deserting females was constrained by their not allowing the females to remate. In a more general model by Webb et al. (in press), a deserting female can remate and renest within the same breeding season. Interestingly, their model found that a female deserts not only when her reserves are low (and thus she is threatened by starvation) but also when her reserves are high. In the latter case, the deserting female immediately starts to search for a new mate and thus increases her reproductive success by remating.

In many birds, fish, and mammals, however, the payoffs from caring and deserting not only depend on the environment and the energy reserves of the parents but also on the behavior of other animals in the population. First, the success of the current breeding attempt depends on whether the focal animal's mate cares or deserts. Second, the operational sex ratio (Emlen and Oring 1977) can determine the time to remate and hence influence the payoff from desertion. There is evidence that animals respond to the operational sex ratio. For example, male fish more often terminate care if the sex ratio is biased toward females (Keenleyside 1983; Balshine-Earn and Earn 1998), and female rock sparrows Petronia petronia desert their brood in years when many unmated males are in the population (Pilastro et al. 2001). These aspects of parental care require a game-theoretic analysis (Maynard-Smith 1982; Hammerstein and Parker 1987) in which the behavior of the focal pair as well as other members of the population is considered. The importance of including the behavior 
of other members of the population is illustrated by Webb et al. (1999). They show that modeling the behavior of a single pair in isolation from the rest of the population results in different evolutionarily stable strategies (ESSs) from ones in which future expectations, including remating probabilities, depend on the behavior of all members of the population. Taken together, a full understanding of parental care requires an analysis that is both state dependent and game theoretic. For a related discussion in the context of alternative reproductive behaviors, see Alonzo and Warner (2000).

Here, we develop a state-dependent game model in which the parents' decisions depend on their own energy reserves, their mate's reserves, and time in the season. The payoffs for performing each action are not specified in advance, since they depend on future expectations, which, in turn, depend on the future behavior of the focal animal and the behavior (both past and future) of other population members. We use the model to show that statedependent models can produce very different predictions from state-independent ones because they allow the animals to optimize simultaneously their behavior and reserves. We then investigate how the energetic costs of various activities (e.g., parental care, reproduction, mate search), care parameters, and the population sex ratio influence parental decisions.

\section{The Model}

We consider the behavior of a focal male and a focal female in a large population of $N_{\mathrm{M}}$ males and $N_{\mathrm{F}}$ females $(N=$ $N_{\mathrm{M}}+N_{\mathrm{F}}$ ) during a breeding season of $T \mathrm{~d}$. For simplicity, we only describe the behavior of a focal male. If we do not explicitly specify the female's behavior, then similar reasoning applies to her too. For a technical account of the model, see appendices A and B.

The state of a focal male is represented by his marital status (unmated or mated), his energy reserves, and, if he is mated, the energy reserves of his mate. The male dies of starvation if his reserves fall to zero. However, his reserves cannot increase above some maximal level. All changes in reserves are stochastic.

All animals are unmated when they arrive at the breeding ground. Members of the population arrive gradually (i.e., on a given day, only a proportion of the whole population arrives). The expected reserves of an arriving individual may depend on its date of arrival.

The available behavioral actions of a male depend on his marital status. If a male is unmated at the beginning of a given day, then he can rest, forage, or search for a mate during that day. Resting does not change the reserves of the male, whereas foraging increases his reserves. The extent of this increase depends on the efficiency of foraging (i.e., the net energy gained in a day). Searching for a mate decreases the reserves of the male, but he may find a mate. The mate-finding probability of a male depends on the number of mate-searching individuals of both sexes (Webb et al. 1999). To illustrate this, let us assume that only a few females are searching for a mate. If only the focal male searches for females, he will find one with high probability despite their low numbers. However, if many males search, the focal male's probability of finding a mate will be low. The probability of finding a mate also depends on the mate-search efficiency $k$, which may reflect population density (McNamara et al. 2000). If the focal male finds a mate, he becomes mated. We assume that mate-finding is random (i.e., there is no mate choice). As a consequence, the level of energetic reserves of the mate is drawn from the distribution of the reserves of the unmated matesearching females (i.e., at the time of pair formation, one member of the pair has no information about the energy reserves of its partner).

Once a pair has formed, they then produce some offspring after a fixed period. For example, in birds, this period may represent the time required to prepare a nest or to produce eggs. Producing offspring reduces the reserves. This could represent the energetic cost of nest building, territory defense, or egg laying. We assume that if the reserves of the male's mate are not high enough to cover this cost, then she dies and no offspring are produced. The male then becomes unmated after the time period needed for offspring production.

Having produced the offspring, both members of the pair decide whether to care for the offspring until they become independent or to desert (i.e., we assume that the animals decide once for each breeding attempt). We assume that by this time, each parent has been able to observe the energy reserves of its partner. Thus, when making decisions, both parents know each others' reserves exactly. The male decides first, and the female then decides on the basis of her partner's decision. This is a reasonable assumption in internally fertilizing animals such as birds, mammals, and some fish because the male can leave the family immediately after fertilization, whereas the female has to wait to finish offspring production (e.g., laying the eggs or giving birth). If the male deserts, his reserves remain unchanged and he will be unmated the beginning of the next day (i.e., he has again the choice of resting, foraging, or searching for a mate). If the male cares, he remains with the offspring until they become independent, or he dies of starvation. Care is costly in terms of both time (since the caring parent is not available for remating) and energy. The energetic cost to a parent is, however, typically less if both parents care for the offspring (cost of biparental care) than if the parent cares alone (cost of uniparental care). If a caring parent dies of starvation, we 
consider the consequences for the brood to be as if that parent had not cared at all. For instance, if both parents decide to care but the female dies during care, then the brood receives male-only care. In this case, the male's reserves decrease by the cost of uniparental care instead of by the cost of biparental care. Although the consequences of starvation have to be taken into account, we emphasize that for the parameters used, starvation almost never occurs.

When the offspring become independent, their contribution to the male's reproductive value is $R_{\mathrm{AB}}(x, y, t)$. We assume that this reproductive value of offspring depends on the pattern of care they receive $A B$, the time in the breeding season $t$, and in some cases, the parents' reserves $x$ and $y$. There are four possible patterns of care: no care (i.e., both parents desert, DD); male-only care (i.e., the male cares and the female deserts, CD); female-only care (i.e., the male deserts and the female cares, DC); and biparental care (i.e., both parents care, CC). We are interested in species in which at least some care is essential for the offspring to reach independence; therefore, we assume that the offspring die if both parents desert (i.e., $\left.R_{\mathrm{DD}}[x, y, t]=0\right)$. Furthermore, the young typically have their highest reproductive value when they are cared for by both parents so that $R_{\mathrm{CC}} \geq R_{\mathrm{CD}}, R_{\mathrm{DC}} \geq R_{\mathrm{DD}}$. The effect of uniparental care on the value of offspring is characterized by the care parameters (baseline values given in table $1)$. The offspring's reproductive value is assumed to decrease with time in the season to account for the general trend in birds that offspring produced late in the season have lower reproductive success than offspring produced early (Daan et al. 1989; Székely and Cuthill 1999). In the baseline case, the reserves of the parents have no effect on the reproductive value of the young. We also investigate cases in which the reproductive value of the offspring increases with the reserves of the caring parent(s).

If the male survives until the end of the breeding season, he receives an additional reward that represents his reproductive success in future breeding seasons. This terminal reward is taken to be independent of his reserves.

\section{The Desertion Game}

We consider a population whose members follow a policy $\pi$. We refer to this policy as the "resident policy" (McNamara et al. 1997, 2000). Given this policy and some initial distribution of reserves, we calculate the number of mate-searching males and females, the distribution of their reserves, and, consequently, the probability of finding a mate with given reserves for all days in the breeding season. On the basis of these distributions, we can determine the optimal policy for a "mutant" by solving the dynamic programming equations backward from the end of the
Table 1: Parameters of the model and their baseline values

\begin{tabular}{llc}
\hline Parameter & Symbol & Value \\
\hline Length of the breeding season (d) & $T$ & 100 \\
Duration of offspring production (d) & $t_{1}$ & 4 \\
Age of offspring at independence (d) & $t_{\mathrm{c}}$ & 10 \\
Maximum value of reserves & $L$ & 25 \\
Efficiency of mate search & $k$ & .3 \\
Value of no care & $V_{\mathrm{DD}}$ & 0 \\
Value of male-only care & $V_{\mathrm{CD}}$ & .7 \\
Value of female-only care & $V_{\mathrm{DC}}$ & .7 \\
Value of biparental care $_{\text {Net energy gain while foraging }}$ & $V_{\mathrm{CC}}$ & 1 \\
Energetic cost of resting $^{\mathrm{a}}$ & $x_{\mathrm{f}, \mathrm{M}}$ & 2 \\
Energetic cost of mate searching $^{\mathrm{a}}$ & $x_{\mathrm{r}, \mathrm{M}}$ & 0 \\
Energetic cost of offspring production $^{\mathrm{a}}$ & $x_{\mathrm{s}, \mathrm{M}}$ & 1 \\
Energetic cost of desertion $^{\mathrm{a}}$ & $x_{\mathrm{l}, \mathrm{M}}$ & 3 \\
Energetic cost of biparental care $^{\mathrm{a}}$ & $x_{\mathrm{d}}$ & 0 \\
Energetic cost of uniparental care $^{\mathrm{a}}$ & $x_{\mathrm{c}, \mathrm{M}}(\mathrm{C})$ & 10 \\
Dependency of offspring value on reserve $_{\mathrm{c}, \mathrm{M}}(\mathrm{D})$ & 12 \\
Number of males $_{\text {Number of females }}$ & $N_{\mathrm{M}}$ & 0 \\
Median arrival time & $N_{\mathrm{F}}$ & 5,000 \\
\hline Notion & & 6 \\
\hline
\end{tabular}

Note: The sexes are not different under the baseline case, so we give only the values for the male.

${ }^{a}$ Variable is set to zero in the reserve-independent scenario.

breeding season. We call this optimal policy the "best response" $B(\pi)$ to the resident population strategy $\pi$ (McNamara et al. 1997, 2000). A necessary condition for a strategy $\pi^{*}$ to be an evolutionarily stable strategy (ESS) is that it is a best response to itself (i.e., $B\left[\pi^{*}\right]=\pi^{*}$ ).

To calculate the ESS, we use a technique commonly called the "iteration of the best response map." This starts with an arbitrary strategy $\pi_{0}$ and finds the sequence $\left(\pi_{0}\right.$, $\left.\pi_{1}, \pi_{2}, \ldots\right)$ of strategies where each strategy is the best response to the previous strategy in the sequence (i.e., $\left.B\left[\pi_{i}\right]=\pi_{i+1}\right)$. The sequence converges to a limiting strategy $\pi^{*}$ in some cases, but it fails to converge in others. The problem arises because the best response $B(\pi)$ does not change continuously with $\pi$. To overcome this difficulty, we use damping and errors in decision making (for further details, see McNamara et al. 1997). The error is controlled by the parameter $\delta$. When $\delta=0$, the animals do not make any errors, whereas with increasing $\delta$, the animals are increasingly unable to differentiate between actions with similar consequences. We use a small error $(\delta=0.015)$ that produced the evolutionarily stable solutions in all cases. These stable solutions give the optimal policies of males and females over the breeding season. We consider a population in which these policies are used. Following the population forward in time gives the distribution of reserves of population members and the proportion of population members taking each action at each time in the breeding season. (Note this is a forward cal- 


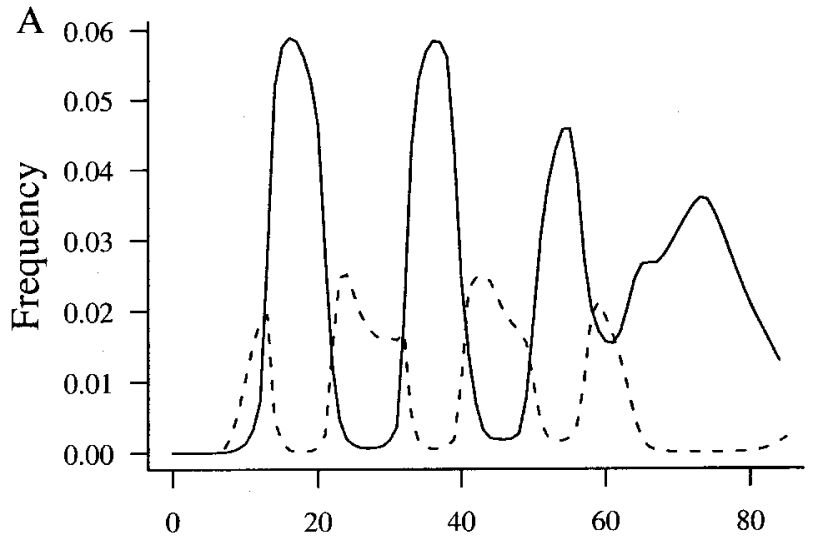

Time, $t$

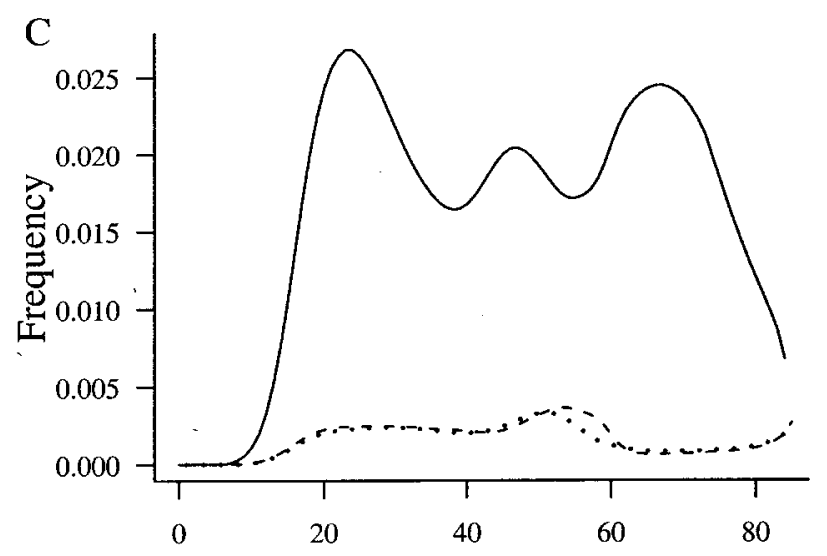

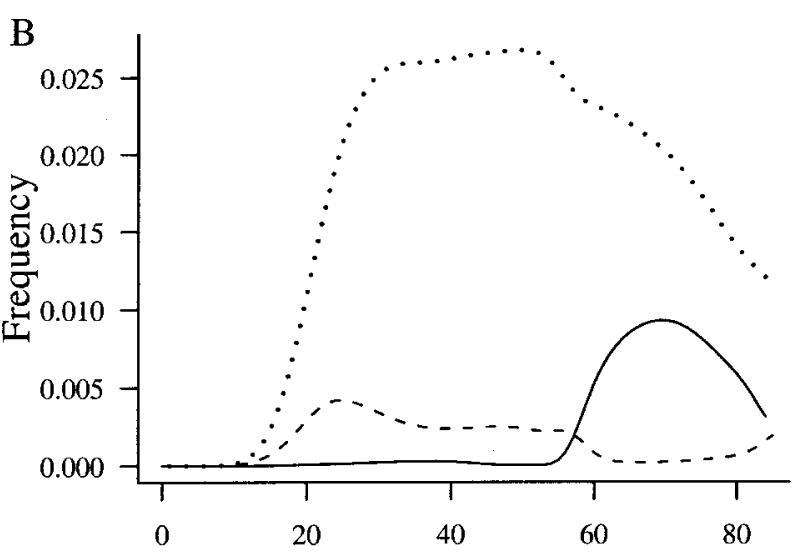

Time, $t$

Time, $t$

Figure 1: The pattern of parental care over the season. $A$, Reserve-independent scenario. $B$, Reserve-dependent scenario: the costs of uni- and biparental care are identical (both $=12$ ). $C$, Reserve-dependent scenario: the costs of care are different (uniparental $=12$; biparental $=5$ ). Solid lines = biparental care; dashed lines = female-only care; dotted lines = male-only care. Other parameters are as in table 1.

culation rather than simulation; see section 3.3 in Houston and McNamara 1999.) The results presented in the figures are based on this computational procedure. For a detailed technical account, see appendix B.

\section{Results}

First, we investigate a reserve-independent scenario. In this scenario, all parameters influencing the animals' reserves (e.g., net energy gain or cost of biparental care; see table 1) are set to zero, and other parameters are kept at their baseline values (table 1). We choose the baseline values such that they allow us to concentrate on the details of the game between the parents. For instance, the sexes are not different from each other, and one parent on its own is reasonably successful at rearing the offspring. Consequently, a conflict of interest arises between the parents because it is more beneficial for an animal to desert than to care, given that its mate will care.

Then we move on to investigate a reserve-dependent scenario by setting the reserve parameters to the values given by table 1, except that the costs of both uniparental and biparental care are 12 units each. Comparison of this case with the reserve-independent case establishes which effects in the reserve-dependent scenario are specifically due to the inclusion of reserves. Finally, we investigate biologically important questions that have been discussed in studies of parental care (Clutton-Brock 1991; Székely et al. 1996) by exploring the effects of changing model parameters.

\section{Reserve-Independent Scenario}

In the reserve-independent case, an oscillation occurs between female-only and biparental care (fig. 1A). This pat- 
tern of care is similar to, and arises for the same reason as, the one predicted by the non-state-dependent dynamic game model of McNamara et al. (2000). We only note here that when female-only care occurs, it is because the male, who decides first, has "forced" the female to care by deserting her. For a full analysis, see McNamara et al. (2000).

\section{Reserve-Dependent Scenario}

Restoring the effects of reserves has a major effect on the pattern of care (fig. 1B). Given that the costs of uni- and biparental care are the same, male-only care is the most common form of care even though the male decides first. Biparental care is frequent only near the end of the breeding season (fig. $1 B$ ).

The reason for the difference between the reserveindependent and the reserve-dependent scenarios is as follows. In the reserve-independent scenario, the male can force the female to care by deserting her because he decides first (McNamara et al. 2000). In the reserve-dependent scenario, an animal can only raise the young and survive the period of care if it starts to care with reserves higher than a critical level (the sum of the cost of parental care and a safety margin serving as an insurance against the stochasticity in reserve dynamics). Consequently, in this case, the male can only force his mate to care by deserting if the female has reserves higher than her critical level; otherwise, she also deserts in order to avoid starvation. Therefore, the inclusion of reserves creates an opportunity for the female to circumvent the male's intended behavior by keeping her reserves below the critical level. If the female does this, she will have to desert whatever the male does. Thus, if the young are not to die, the male must ensure that he has sufficiently high reserves to care. Conversely, assume that the male has high reserves. Then, if the female were to have high reserves, the male would desert, thus forcing the female to care. It follows that the female's best strategy is to have low reserves, thus forcing the male to care. From this argument, it can be seen that the pattern of high reserves for the male and low reserves for the female (see fig. 2A) is evolutionarily stable.

Is it possible that there are other stable patterns; in particular, could it be stable for a male to have low reserves and hence force the female to care? If females have high reserves, then it is optimal for males to exploit this fact by deserting, so forcing the female to care. (Note the asymmetry here; the female could not force a male with high reserves to care because such a male would have deserted by the time she made her care decision.) But if a male is going to desert, it is better if he has high reserves. This is primarily because high reserves mean that he can devote his time to searching for a mate rather than foraging. We

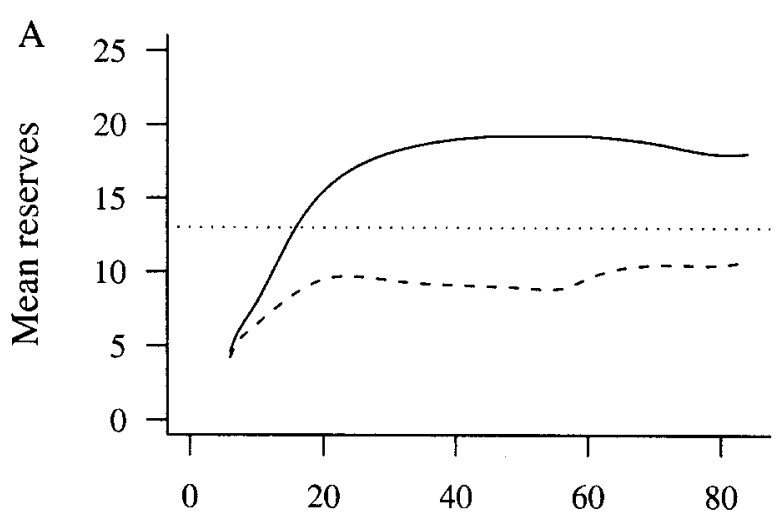

Time, $t$

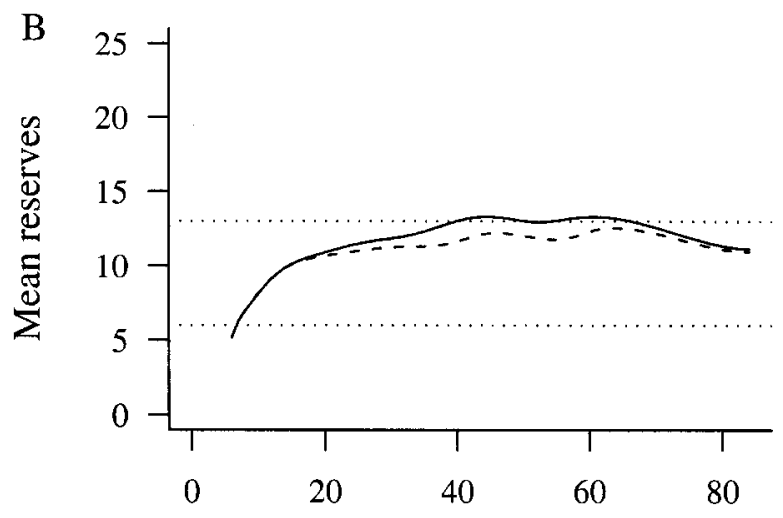

Time, $t$

Figure 2: The mean reserves of mated males (solid lines) and females (dashed lines) over the breeding season. The costs of uni- and biparental care are $(A)$ identical (both $=12$ ) and $(B)$ different (uniparental $=12$; biparental $=5$ ). The dotted lines mark the critical levels of reserves.

have already seen, however, that if males have high reserves, then it is best for females to have low reserves. It follows that low reserves for females and high reserves for males is the unique stable pattern of reserves. The outcome of this pattern is uniparental care by the male.

\section{Difference between Energetic Costs of Uni- and Biparental Care}

Until now, we have investigated the case in which the energetic costs of uni- and biparental care are the same. This may be a reasonable assumption for species with less demanding young (e.g., birds with precocial chicks). In contrast, the costs of uni- and biparental care may significantly differ in species that have more demanding young (e.g., birds with altricial chicks). We investigate the effects of the difference between these costs by keeping the 
cost of uniparental care at its baseline value and decreasing the cost of biparental care.

When the difference between these costs is small $(<5)$, then the female can use her strategy of reserve regulation to force her mate to care; thus, the result is male-only care during most of the season (results are similar to those shown in fig. $1 B$ ). In contrast, when the difference between these costs is large, the male can circumvent the female strategy by keeping his reserves at an intermediate level, and this results in biparental care (figs. 1C, $2 B$ ).

The occurrence of biparental care when the difference between costs is large can be understood as follows. We first consider the evolutionarily stable level of reserves for the female. There are three possibilities. She can have high reserves (above the level required for uniparental care), intermediate reserves (below the level for uniparental care but above the level for biparental care), or low reserves (below the level for biparental care). Note that a female with high reserves can care on her own, with intermediate reserves she can only care together with her mate, whereas with low reserves she cannot care. Suppose that the female has high reserves. Then, the best action for the male is to desert, leaving the female to care. Given that he is going to desert, it is best for the male to have high reserves. But then the female should reduce her reserves below the level for uniparental care, forcing the male to care. Thus, there can be no ESS in which the female has high reserves. Now, suppose that the female has low reserves. She then always deserts whatever the decision of the male. The male is forced to care in these circumstances, and given this, it is best if he has high reserves. But the best action of a male with high reserves is to care not only if the female has low reserves but also if she has intermediate reserves. So given this behavior of the male, it is best for the female to have reserves as high as possible while still forcing the male to care. Thus, she should have intermediate reserves. It follows that there is no ESS in which the female has low reserves; if an ESS exists, the female must have intermediate reserves.

What, then, is the stable level of reserves for the male? In line with the above reasoning, let the female have intermediate reserves. The male then has to care. Given this, he can have high reserves, in which case the female will desert and he will care on his own, or intermediate reserves, in which case the female will be forced to care as well. Since in the baseline case biparental care is significantly better than uniparental care, and he must care whatever happens, the male's best strategy is to have intermediate reserves. The resulting ESS is for both the male and the female to have intermediate reserves and for both to care (figs. $1 C, 2 B$ ).

The male, however, should only reduce his reserves to intermediate levels when his mate is expected to have in- termediate levels of reserves. Even if the female attempts to keep her reserves in this region, she cannot reliably do so when the critical levels of uniparental and biparental care are close because of stochasticity in the dynamics of reserves. This explains why male-only care occurs at small differences between the costs of uni- and biparental care. In particular, for the parameter values given in table 1, the difference in costs is small, and there is male-only care for much of the season. Since results for these parameters are very similar to those given in figures $1 B$ and $2 A$, they are not shown. When the difference is large, however, the male can safely reduce his reserves and biparental care is the result.

\section{Energetic Cost of Reproduction}

We manipulated the energetic cost of reproduction (the sum of energetic costs of offspring production and parental care) by varying either the cost of offspring production or the cost of parental care in such a way that the difference between the costs of uni- and biparental care remains as in table 1. If the energetic cost of reproduction is significantly less than the maximal reserves, the female forces the male to care in the same way as seen previously. If the cost of reproduction for one sex approaches the maximal level of reserves, then that sex deserts more often than the other sex. If an animal's cost of reproduction exceeds its maximal level of reserves, then it always deserts.

\section{Energetic Cost of Mate Search}

As the energetic cost of mate search increases, a single individual must spend a greater proportion of time on foraging. As a consequence, the time needed to find a new mate increases, so the number of broods produced over the breeding season decreases (fig. $3 A$ ).

We separately investigate symmetric cases (the search cost is the same for both sexes) and asymmetric cases (the search cost is different for the sexes). In symmetric cases, if the search cost is low, the females desert more often than the males (fig. $3 B$ ). This is because the females keep their reserves low (fig. $3 C$ ) to force the males to care. If the search cost is high, the sexes do not exploit each other (fig. 3B). Large search cost means that it is more difficult to maintain high reserves. Hence, the males' reserves decrease (fig. $3 C$ ), which in turn makes them less vulnerable to exploitation by the females. Another consequence of the low level of reserves is that the frequency of biparental desertion increases with search cost. The animals do not know the reserves of their mates in advance, and if the average level of reserves in the population is low, both members of the pair are more likely to find themselves 

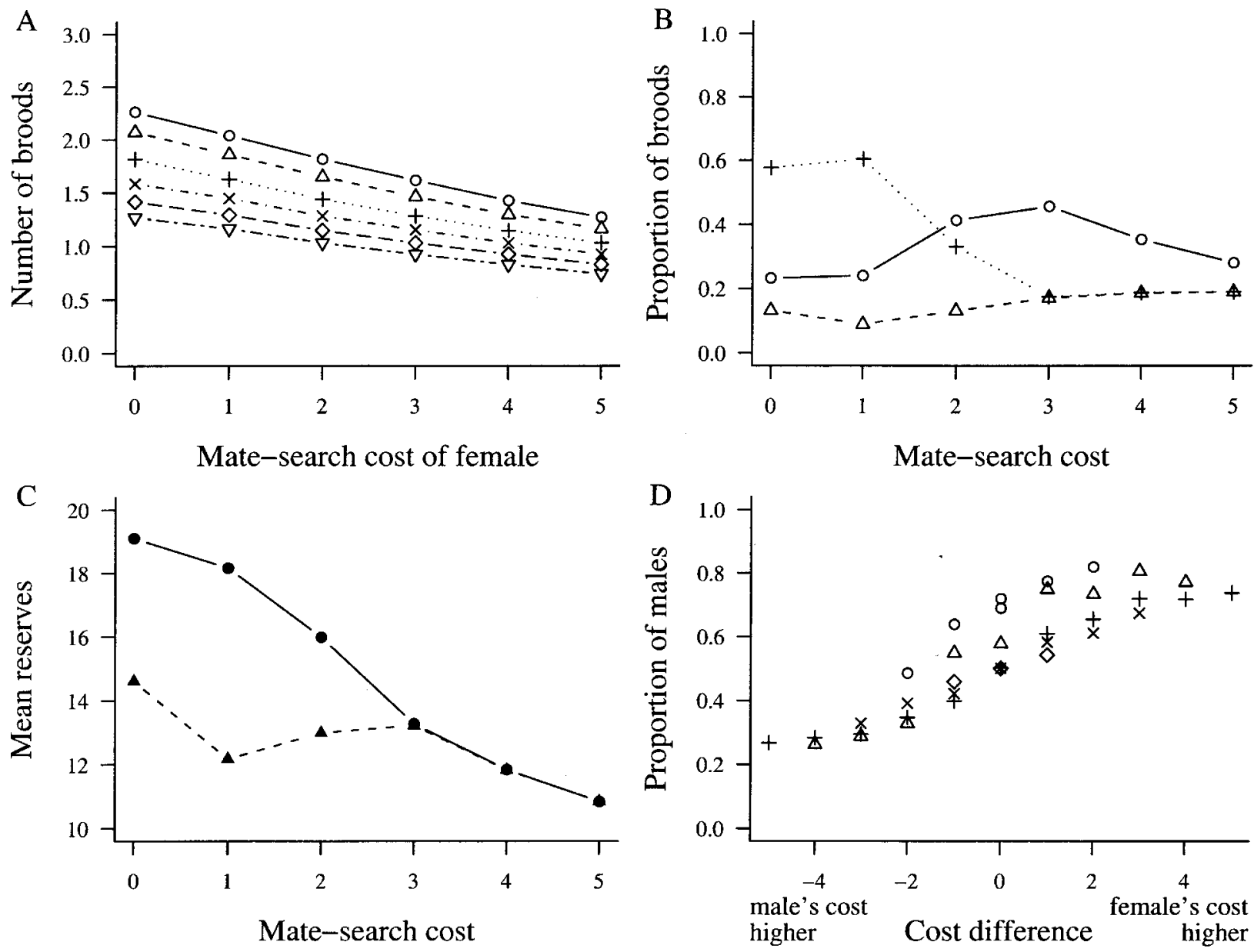

Figure 3: The effects of mate-search cost. $A$, The expected number of broods produced during the breeding season plotted against the mate-search cost of females at different values of mate-search cost of males ( ircle $=0$; triangle $=1$; plus $=2$; cross $=3$; diamond $=4$; inverted triangle $=5$ ). $B$, The pattern of care plotted against the symmetric (same for both sexes) cost of mate search. Proportion of broods produced over the season receiving biparental care (circle), female-only care (triangle), and male-only care (plus) is given. $C$, The mean reserves of mated males (circle) and females (triangle) plotted against the symmetric mate-search cost. Reserves are averaged over the season. $D$, The proportion of caring males to all caring individuals over the season plotted against the difference between the mate-search costs of males and females (average cost of the pair, $c_{\mathrm{a}}$, is given; circle: $c_{\mathrm{a}} \leq 1$; triangle: $1<c_{\mathrm{a}} \leq 2$; plus: $2<c_{\mathrm{a}} \leq 3$; cross: $3<c_{\mathrm{a}} \leq 4$; diamond: $4<c_{\mathrm{a}}$ ).

below the critical levels of parental care, which results in biparental desertion.

In asymmetric cases, the sex with the higher search cost deserts more often than the sex with lower cost (fig. 3D). This result is counterintuitive because high search costs decrease the proportion of time a single animal searches for a mate and hence increases the time to find a mate. Thus, high search costs decrease the advantage of desertion. However, in order to be able to care, an animal has first to raise its reserves above the critical level of parental care, and a high cost of mate search makes it difficult to raise reserves and find a new mate at the same time. Con- sequently, when an animal does mate, its reserves will be low, and it will be unable to care.

\section{Foraging Efficiency}

When the net energy gain while foraging is increased symmetrically for each sex, the baseline pattern of care does not change its qualitative form; male-only care remains the most common type of care, and biparental care occurs close to the end of the season. The details of the pattern of care, however, are changed. Animals start to care earlier in the season. The frequency of biparental care at the end 
of the season increases since it is easier to raise reserves when there is more food, and, hence, less females are below the critical level of biparental care at the end of the season. By changing the net energy gain asymmetrically, the sex that finds more food always cares. This is because the sex that is less efficient at foraging takes longer to replenish the energy spent during care, and, hence, if it was going to care, it would pay a greater cost in terms of future matings.

\section{Effects of Care Parameters}

When the value of uniparental care by both sexes is low $\left(V_{\mathrm{CD}}, V_{\mathrm{DC}} \leq 0.5\right)$, neither parent can effectively raise the young on its own so both parents care (fig. 4). Increasing the value of uniparental care leads to increased temptation for desertion and increased frequency of uniparental care. When the increase is symmetric, the female can exploit the male by keeping her reserves low, and male-only care is the result (fig. 4). When the increase in care parameters is asymmetric, the sex that raises the young less effectively on its own will desert (fig. 4). These results are in accordance with those of McNamara et al. (2000), except that in symmetric cases, they found female-only care when each sex can raise the young effectively on its own.

\section{Search Efficiency and Population Sex Ratio}

Increasing search efficiency, $k$, has a major effect on the pattern of care (fig. 5A). When search efficiency is low (i.e., it is very difficult to find a new mate), the most common form of care is biparental. When the search efficiency increases, the pattern of care changes dramatically; the frequency of deserting females increases, and maleonly care is observed. The reason for this change is the strategic reserve regulation by females; when the payoff from desertion increases, the females reduce their reserves and force the males to care (fig. $5 B$ ).

The effects of population sex ratio $N_{\mathrm{M}}: N_{\mathrm{F}}$ depend on the search efficiency. When the search efficiency is low, the sex ratio has no effect on the pattern of care (fig. 6A) since desertion is not beneficial even at very extreme sex ratios $\left(N_{\mathrm{M}}: N_{\mathrm{F}}=3: 1\right.$ or $\left.1: 3\right)$. When the search efficiency is high, the payoff from desertion increases. The proportion of male-only care increases, whereas the proportion

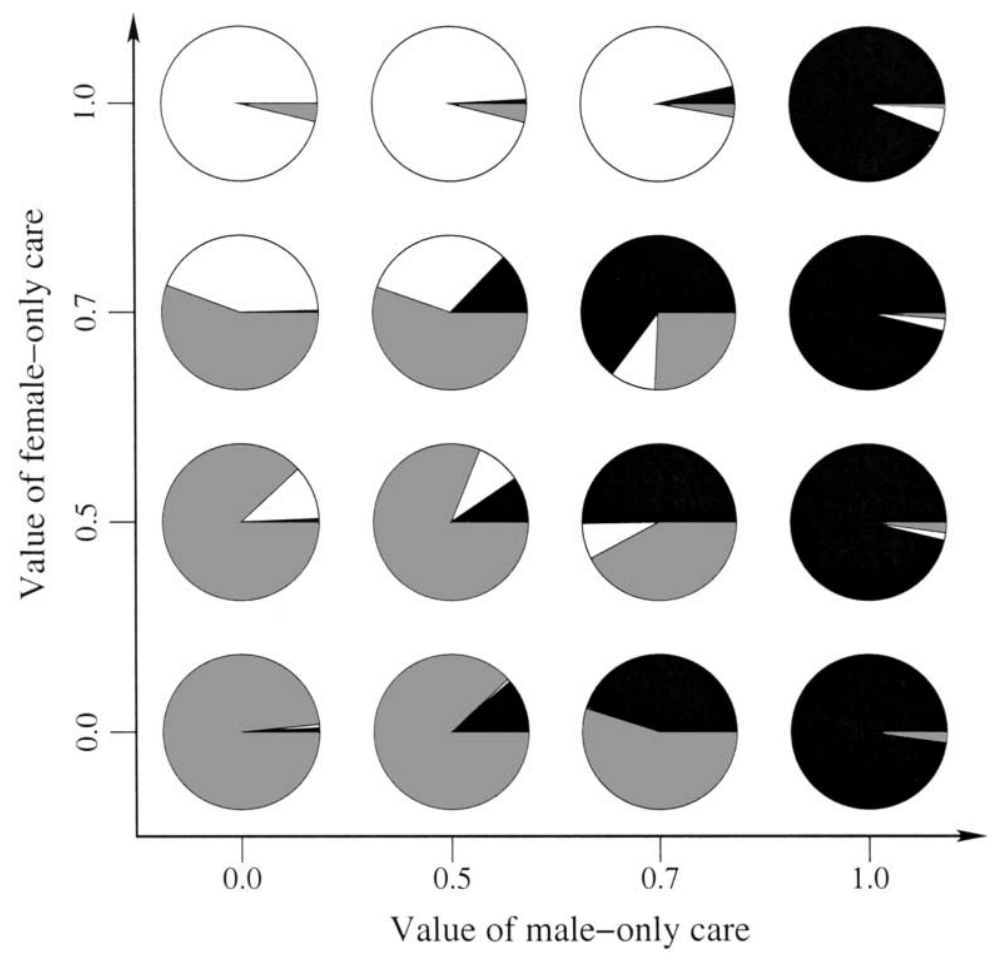

Figure 4: The pattern of care plotted against the values of uniparental care of each sex. Each pie chart shows the proportion of broods that receive female-only (white), male-only (black), or biparental (grey) care during the breeding season. The frequency of biparental desertion was negligible in all cases. 

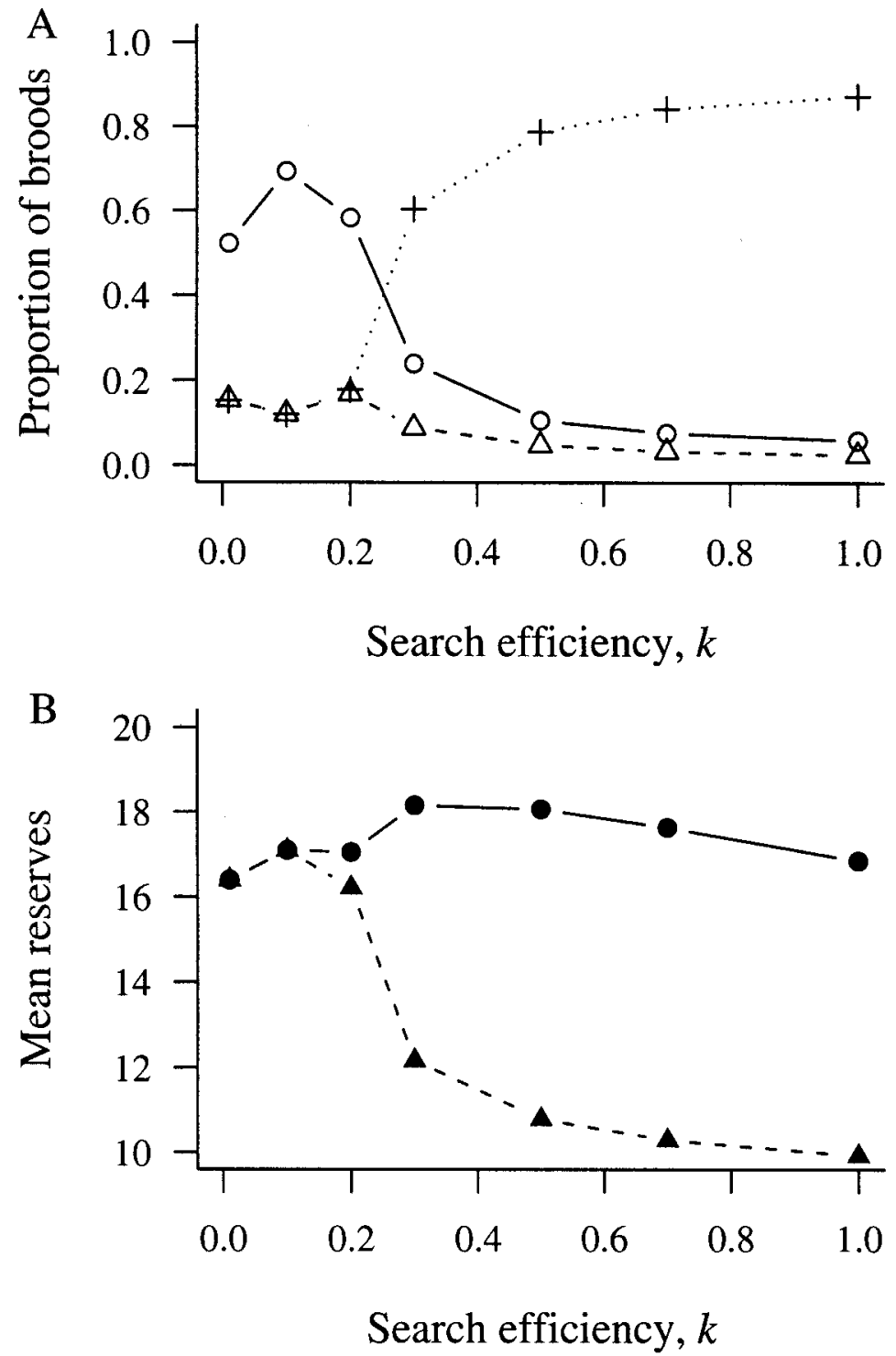

Figure 5: The effects of search efficiency $k$. A, The proportion of broods receiving biparental (circle), female-only (triangle), and male-only (plus) care. $B$, The mean reserves of males (circle) and females (triangle).

of female-only and biparental care decreases as the sex ratio shifts from female biased to male biased (fig. 6B). This result agrees with previous models (e.g., Maynard Smith 1977; McNamara et al. 2000). Unlike these models, however, in our model, even in a strongly female-biased $\left(\mathrm{N}_{\mathrm{M}}: N_{\mathrm{F}}=1: 3\right)$ population, male-only care is more common than female-only care. This result arises because the strategic reserve regulation by females overcomes the effect of sex ratio.
Value of Brood Depends on Parental Reserves

So far, we have assumed that the value of the brood is independent of parental reserves. One can argue, however, that parents with high reserves can provide better care than parents with low reserves. We investigate this possibility by letting brood reproductive values increase with parental reserves (see app. B). If the reproductive value of the offspring depends strongly on the reserves of the caring 


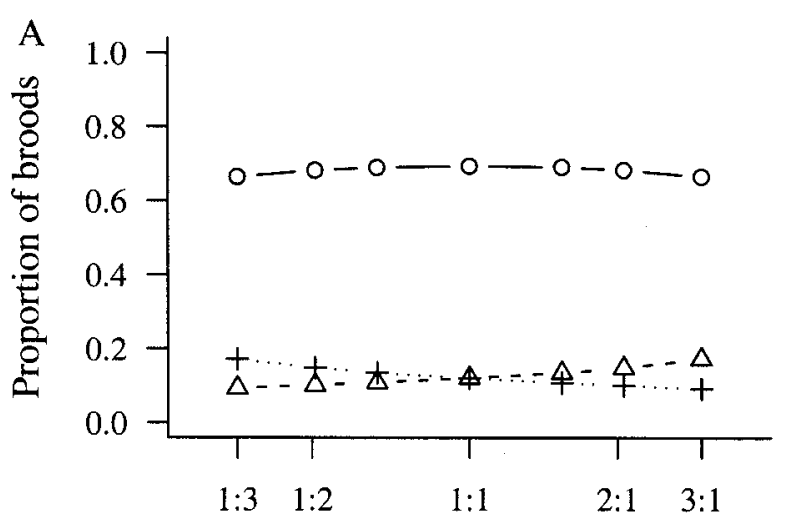

Sex ratio (M:F)

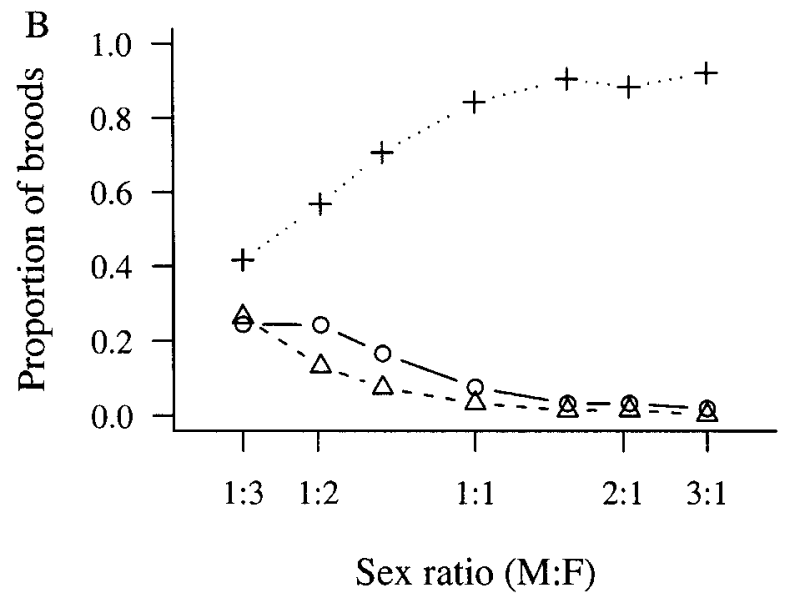

Figure 6: The effects of population sex ratio $N_{\mathrm{M}}: N_{\mathrm{F}}$ when the searching efficiency is $(A)$ low $(k=0.1)$ and $(B)$ high $(k=0.7)$. For symbols, see figure $5 \mathrm{~A}$.

parent(s) $(h>0.2)$, biparental care is the most common form of care during the season (fig. $7 A$ ). The reason for this result is that strong reserve dependence leads to the elimination of strategic reserve regulation, as shown by the increasing reserves of females with reserve dependence (fig. $7 B$ ), since by strategically reducing the reserves, the parents pay a cost in terms of reduced brood value. If the dependence is weak $(h \leq 0.2)$, females still use regulation of reserves to force the males to care.

\section{Discussion}

Our state-dependent dynamic game model shows that the strategic regulation of body mass can have important effects on the solution of sexual conflict over parental care. When reserves are not included in our model, members of the sex deciding first (labeled as males) force the members of the other sex (labeled as females) to care by deserting. In contrast, when the reserves have effects and the difference between the costs of uni- and biparental care is small, the female circumvents the intended behavior of the male by keeping her energy reserves low. Thus, even though the male decides first, he cares instead of deserting. Furthermore, when the difference between the costs is large, each sex avoids being exploited by keeping its reserves between the level required for biparental care and the level required for uniparental care. This is a novel form of strategic body mass regulation that arises only in a game-theoretic context (i.e., animals reduce their reserves in order to manipulate their mate's behavior). Previous studies of strategic body mass regulation focused on single

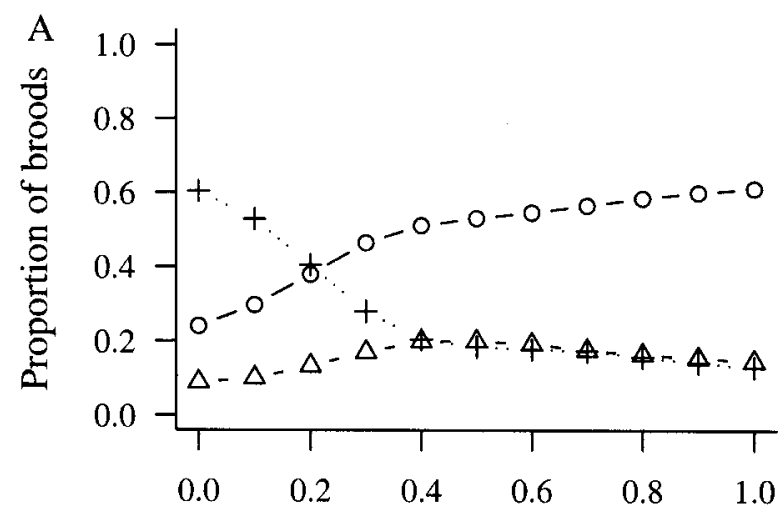

Reserve dependency, $h$

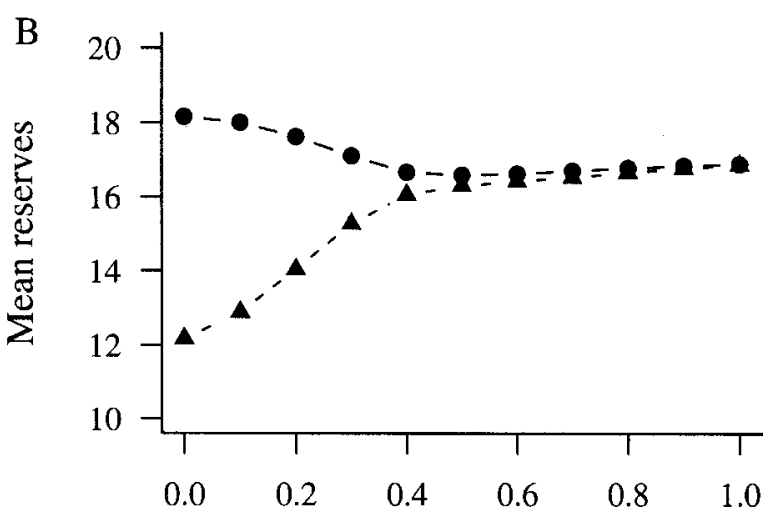

Reserve dependency, $h$

Figure 7: The effects of the dependency $h$ of offspring value on the reserves of the parent(s). If $h=0$, the brood reproductive value does not depend on the parental reserves. As $h$ increases, the value of having high reserves increases. $A$, The proportion of broods receiving biparental (circle), female-only (triangle), and male-only (plus) care. B, The mean reserves of males (circle) and females (triangle). 
individuals and investigated the various costs (e.g., increased predation hazard) and benefits of carrying fat (reviewed by Witter and Cuthill 1993; Cuthill and Houston 1997).

A threat must be credible in order to settle a conflict between animals. For example, imagine a male and female deciding about whether to care or desert as in our model. Suppose that the energetic costs of care can be ignored, and it is more beneficial for an animal to desert than to care, given that its mate will care. Then a pair of mutual best responses, that is, a Nash equilibrium, is for the male (who decides first) to care and the female (who decides second) to desert whatever the male decides. In this case, the female is forcing the male to care by means of the threat of desertion even if the male deserts. Although these strategies are a Nash equilibrium, they are not evolutionarily stable (Houston and McNamara 1999). Consider the alternative female strategy: desert if the male cares and care if the male deserts. Given that the male always cares, this strategy for the female has exactly the same payoff as always deserting. It follows that this alternative strategy can increase by random drift (cf. Selten 1980). Furthermore, if males make mistakes and desert (or do not care because, unknown to the female, they have been killed), then the alternative strategy is strictly better for the female. For these reasons, the alternative strategy can be expected to increase in the population up to a level at which it becomes better for males to exploit this strategy by deserting (Houston and McNamara 1999). Thus, in evolutionary terms, the threat of desertion by the female even if the male deserts is not credible. Once reserves are included, the above argument no longer holds. If a female keeps her reserves below the level required for uniparental care, then her best action when deserted is also to desert. It follows that the threat of desertion by a female with low reserves is now credible. As a result, there is an evolutionarily stable solution in which the female forces the male to care by keeping her reserves low.

Many birds often lose mass during breeding (reviewed by Moreno 1989). This change is traditionally interpreted as either a sign of stress (Ricklefs 1974; Nur 1984) or an adaptation to increase flight efficiency during a demanding period of brood rearing (Freed 1981; Norberg 1981; Houston 1993; Hillström 1995). Our model raises the possibility of a novel explanation for this mass loss; the parents lose mass to manipulate their mate's behavior. If this explanation is correct, we might expect that a female would increase her level of reserves when her mate is removed. In our current model, there is only a single decision per breeding attempt, so such an effect cannot be predicted. In reality, birds are likely to make a sequence of state- and time-dependent decisions. Further theoretical work is necessary to estab- lish the implications of using mass loss to generate credible threats in a realistic context.

It is widely accepted that the ability of one parent to raise the young limits the possible patterns of care (Lack 1968; Temrin and Tullberg 1995). For instance, if a single parent is able to provide appropriate care for the offspring, then uniparental care is expected. It has been found, however, that in many species with biparental care, one parent can raise the young nearly as successfully as both parents (Bart and Tornes 1989; Wolf et al. 1990; Liker 1995). Interestingly, our model predicts that, despite the fact that one of the parents can raise the young efficiently, the pattern of care can still be biparental if the difference between the costs of uniand biparental care is large. Then both sexes can avoid being deserted by keeping their reserves at an intermediate level.

Our model reveals that, as a consequence of the effects of reserves, the parameters that influence reserves before mating (e.g., foraging efficiency, cost of mate search) can have a large effect on the pattern of parental care. In general, the sex that can improve its reserves more efficiently or pay less energetic cost will care. This emphasizes that one cannot investigate the behavior of unmated or mated individuals in isolation from each other (Webb et al., in press).

It could be argued that three of our assumptions may limit the generality of the results on strategic regulation of body mass. First, we assume that each animal knows exactly the reserves of its mate. This expectation is probably unrealistic, especially in cases when the male and female interact only briefly. Note, however, that the level of reserves is set while the individuals are unmated (i.e., before they mate). Therefore, the male's behavior can be an evolutionary response to the female's expected low reserves (and vice versa), in which case it is unnecessary to assume that the pair members should be aware of each other's reserves. Consequently, the assumption that mated animals know each other's reserves exactly in our model may not have a crucial effect on the results. Our second assumption is that an animal must have reserves higher than a certain limit before breeding in order to breed successfully. Stearns (1992) defines a capital breeder to be an organism that uses stored energy for reproduction and an income breeder to be an organism that uses energy that it obtains during the reproductive period rather than stored energy for reproduction. Our model applies to capital breeders. It does not apply to a pure income breeder in which energy reserves at the start of reproduction make no contribution. This pure form of income breeding may be rare. There is a continuum of breeding patterns from pure capital breeding to pure income breeding (Thomas 
1989; Stearns 1992). Our model applies to forms of breeding along this continuum provided that for low reserves, income is not enough to cover costs, so that individuals whose reserves are sufficiently low at the beginning of care are likely to starve during care. We emphasize that the existence of a critical level of reserves does not mean that offspring desertion due to low reserves can be observed frequently in nature since animals follow policies that make such desertion unlikely. The third assumption is that mate choice is random. It might be suggested that a female can use strategic body mass regulation if the male does not know the reserves of his prospective mate at the time of pair formation. If, however, the male knew the reserves of his future partner, he could potentially avoid mating with a female with low reserves. Therefore, in a population of choosy males, females should have high reserves. If all females have high reserves, however, it is no longer worth choosing among females especially if choosiness incurs a nonzero cost. Consequently, nonchoosy males can spread into the population, creating an opportunity for the females to use strategic body mass regulation. Therefore, the population of choosy males and females with high reserves cannot be stable, so mate choice may not prevent the use of strategic body mass regulation. Further theoretical work is needed, however, to explore the detailed effects of the role of information and the inclusion of mate choice in our model.

A consequence of random mate choice is that biparental desertion occurs, especially when the average level of reserves in the population is low. In this case, the individuals do not know the reserves of their prospective partner, and hence, it may turn out that neither parent can cover the cost of care, which in turn leads to biparental desertion. Similarly, Webb et al. (1999) find that uncertainty about the quality of a partner can result in biparental desertion.

Strategic regulation of reserves has far-reaching consequences in our model. For instance, there is more desertion by females than by males even in a population with a strongly female-biased sex ratio. Consequently, our model predicts male-only care for a large parameter space. This prediction is different from the empirical findings that female-only care is more common than male-only care in most animals (Clutton-Brock 1991). We suggest a number of reasons for this discrepancy. First, the sexes are typically more asymmetric in nature than we assume during the computations. For instance, males often have higher costs of mate search than females. Also, care by the female may be much more beneficial to the young than care by the male (e.g., lactation in mammals). For these asymmetric cases, the model predicts female-only care. In addition, our model has no scope for males to monopolize access to groups of females.

Details of the decision process may also influence our results. First, we assume that the male decides first. In nature, the opposite can also hold (i.e., the female decides first). For instance, in externally fertilizing animals such as many fish and amphibians, the female releases the gametes first (Dawkins and Carlisle 1976). Second, we assume that the pair decides about care only once during a breeding attempt. In reality, the decision process is probably more complicated; it may involve a series of interactions between the male and female. Therefore, the final outcome (i.e., the observed pattern of care) can be the result of this prolonged negotiation process. For instance, in the Kentish plover Charadrius alexandrinus, the parents alternate care of the brood until one parent deserts. These shifts may be part of the negotiation process in which the parents test their own abilities to attract a new mate and renest as well as testing the ability of their mate to care for the brood unassisted (T. Székely, personal observation). The effects of these repeated interactions on the pattern of care, however, are not known. It is possible that when the caring and deserting decisions are the results of a long process (e.g., one that lasts for the whole breeding attempt), the caring female can use the strategic body mass regulation to ensure that her mate does not desert. These arguments emphasize that the decision process itself requires detailed future theoretical and empirical studies.

To conclude, our model predicts that strategic regulation of body mass has an important role in the solution of sexual conflict in parental care. A fundamental effect of reserves is that they allow animals to make credible threats.

\section{Acknowledgments}

We thank two anonymous referees for their helpful comments. Z.B. was supported by a Leverhulme Trust Linked Fellowship and a fellowship from the Soros Foundation (Budapest). T.S. was supported by a Natural Environment Research Council grant (GR3/10957) to A.I.H., Innes C. Cuthill, and J.M.McN. The study was also supported by grants from the Hungarian Ministry of Education (FKFP-0470/2000) and the Hungarian Scientific Research Fund (T030434 and T031706). 


\section{APPENDIX A}

\section{Basics}

\section{State Variables and Their Dynamics}

The state of a focal male at time $t$ is represented by his marital status $m_{\mathrm{M}}(t)$, the level of his energy reserves $X_{\mathrm{M}}(t)$, and, if he is mated, the energy reserves of his mate $Y_{\mathrm{M}}(t)$. A male can be either unmated, $m_{\mathrm{M}}(t)=0$, or mated, $m_{\mathrm{M}}(t)=1$. The male's energy reserves $X_{\mathrm{M}}(t)$ take integer values between 0 and $L$. The male dies of starvation if its reserves fall to zero. Any energy that would raise reserves above $L$ is lost. The same constraints apply to the energy level of the male's mate $Y_{\mathrm{M}}(t)$. In defining the dynamics of reserves, we use the truncation function $\operatorname{chop}(x)=$ $\max [0, \min (L, x)]$ (Mangel and Clark 1988).

An unmated male chooses between resting, foraging, or searching for mate. A mated male must either care or desert once the young have been produced. If a male with reserves $x$ on day $t$ rests, then his reserves become $X_{\mathrm{M}}(t+1)=$ $\operatorname{chop}\left(x-x_{\mathrm{r}, \mathrm{M}}-z_{i}\right), x_{\mathrm{r}, \mathrm{M}} \geq 0$, with probability $P_{i}$, where $P_{i}=\{0.25,0.5,0.25\}$, and $z_{i}=\{-1,0,1\}$. If the male forages, then his energy reserves increase; $X_{\mathrm{M}}(t+1)=\operatorname{chop}\left(x+x_{\mathrm{f}, \mathrm{M}}+z_{i}\right)$ with probability $P_{i}$, where $z_{i}$ and $P_{i}$ are defined as above. One can consider $x_{\mathrm{f}, \mathrm{M}}$ the net energy gain during a day; this gain can depend on either the foraging efficiency of the male or the food abundance in the environment. Resting and foraging animals remain unmated (i.e., $\left.m_{\mathrm{M}}[t+1]=m_{\mathrm{M}}[t]=0\right)$.

If a male decides to search for a mate on day $t$, then his marital status will be $m_{\mathrm{M}}(t+1)=1$ (mate found), with probability $P_{\mathrm{M}}(t)$ (defined by eq. [A4]), and $m_{\mathrm{M}}(t+1)=0$ (mate not found), with probability $1-P_{\mathrm{M}}(t)$. If a male does not find a mate, then his reserves are $X_{\mathrm{M}}(t+1)=\operatorname{chop}\left(x-x_{\mathrm{s}, \mathrm{M}}-z_{i}\right)$, with probability $P_{i}$. If he does find a mate, then the pair produce offspring after $t_{1} \mathrm{~d}$, and his reserves at this time will be $X_{\mathrm{M}}\left(t+t_{1}+1\right)=\operatorname{chop}\left(x-x_{1, \mathrm{M}}-z_{i}\right)$, with probability $P_{i}$. Under the assumption of random mating, the reserves of the male's mate is given by the probability distribution of reserves of unmated, mate-searching females: $Y_{\mathrm{M}}\left(t+t_{1}+1\right)=\operatorname{chop}\left(x-x_{1, \mathrm{~F}}-z_{i}\right)$, with probability $P_{i} P_{\text {search, } \mathrm{F}}(x, t)$, where $P_{\text {search, } \mathrm{F}}(x, t)$ gives the probability that a mate-searching female has reserves $x$ at time $t$ :

$$
P_{\text {search, } \mathrm{F}}(x, t)=\frac{P_{\mathrm{F}}(x, 0, t) \pi_{\text {search, }}(x, t)}{\sum_{x=1}^{L} P_{\mathrm{F}}(x, 0, t) \pi_{\text {search } \mathrm{F}}(x, t)},
$$

where $P_{\mathrm{F}}(x, 0, t)$ gives the probability that a female is unmated and has reserves $x$ on day $t$ while $\pi_{\text {search, } \mathrm{F}}(x, t)$ is the probability that an unmated female with reserves $x$ on day $t$ searches for a mate. This latter probability is derived from the females' optimal policy $\pi_{\mathrm{F}}$ (see below). If the male's mate died because of starvation during the laying period (i.e., $Y_{\mathrm{M}}\left[t+t_{1}+1\right]=0$ ), then no brood is produced, and the male becomes unmated at the end of the laying period (i.e., $m_{\mathrm{M}}\left[t+t_{1}+1\right]=0$ ).

After finishing offspring production on day $t$, both members of the pair decide whether to desert or care for the offspring until their independence. An individual who deserts becomes independent $(m[t+1]=0)$, and its reserves are decreased by $x_{\mathrm{d}}+z_{i}, x_{\mathrm{d}} \geq 0$, with probability $P_{i}$.

If a male decides to care for his offspring, then he does so until they become independent after $t_{\mathrm{c}} \mathrm{d}$. Care of the young is energetically costly, and the male's reserves at the end of care are $X_{\mathrm{M}}\left(t+t_{\mathrm{c}}+1\right)=\operatorname{chop}\left[x-x_{c, \mathrm{M}}(\mathrm{A})-z_{i}\right]$, with probability $P_{i}$. The extent of the cost of care depends on whether the mate of the focal male cares $(\mathrm{A}=\mathrm{C}$, biparental care) or deserts $(\mathrm{A}=\mathrm{D}$, uniparental care). Uniparental care may cost more than biparental care (i.e., $\left.x_{c, M}[\mathrm{D}] \geq x_{c, M}[\mathrm{C}]\right)$. Caring for young leads to the production of independent offspring after time $t+t_{\mathrm{c}}+1$ when the caring male becomes unmated; $m_{\mathrm{M}}\left(t+t_{\mathrm{c}}+1\right)=0$.

\section{Arrival}

All males (as well as females) are unmated when they arrive at the breeding ground. The proportion of males arriving on day $t, \Gamma(t)$, is given by

$$
\Gamma(t)=(t+1)^{\alpha_{M}-1} \mathrm{e}^{-\lambda_{\mathrm{M}} t}
$$


This distribution is normalized so that $\sum_{t=0}^{T-1} \Gamma(t)=1$. The approximate mean of $\Gamma(t)$ is $\alpha_{\mathrm{M}} / \lambda_{\mathrm{M}}$, while its approximate variance is $\alpha_{\mathrm{M}} / \lambda^{2}{ }_{\mathrm{M}}$.

The reserves of males that arrive on day $t$ are distributed approximately as a normal distribution with mean, $\mu_{\mathrm{M}}(t)$, and standard deviation, $\sigma_{\mathrm{M}}$. The arriving males' mean reserves depend on $t$ as follows:

$$
\mu_{\mathrm{M}}(t)=\mathrm{A}_{\mathrm{M}}+\mathrm{B}_{\mathrm{M}} t
$$

A similar equation applies to the arriving females. In all of our computations, $\alpha_{\mathrm{M}}, \alpha_{\mathrm{F}}=2 ; \lambda_{\mathrm{M}}, \lambda_{\mathrm{F}}=0.25 ; \sigma_{\mathrm{M}}, \sigma_{\mathrm{F}}=$ $5 ; \mathrm{A}_{\mathrm{M}}, \mathrm{A}_{\mathrm{F}}=5$; and $\mathrm{B}_{\mathrm{M}}, \mathrm{B}_{\mathrm{F}}=0$.

\section{Probability of Finding a Mate}

We assume that the probability that a male finds a mate is given by the following function

$$
P_{\mathrm{M}}(t)=k \sqrt{\frac{N_{\mathrm{F}}(t)}{N_{\mathrm{M}}(t)+N_{\mathrm{F}}(t)} \frac{N_{\mathrm{F}}(t)}{N}},
$$

where $N_{\mathrm{M}}(t)$ is the number of males searching for females, $N_{\mathrm{F}}(t)$ is the number of searching females, $N$ is the population size, and $k$ is the efficiency of searching, $0<k \leq 1$ (McNamara et al. 2000). The values of $N_{\mathrm{M}}(t)$ and $N_{\mathrm{F}}(t)$ are calculated from the distributions of state variables (reserves and marital status) and the optimal strategy of each sex: $N_{\mathrm{M}}(t)=$ $N_{\mathrm{M}}^{\prime} \sum_{x=1}^{L}\left[P_{\mathrm{M}}(x, 0, t) \pi_{\text {search, } \mathrm{M}}(x, t)\right]$, where $N_{M}^{\prime}$ is the number of males currently in the breeding area, $P_{\mathrm{M}}(x, m, t)$ is the probability that a male following the optimal strategy has energetic level $x$ and marital status $m$ at time $t$, and $\pi_{\text {search, } \mathrm{M}}(x, t)$ is the probability of searching for a female. Similar equations apply to the females.

\section{APPENDIX B}

\section{The Game}

\section{Reproductive Value of the Brood}

We consider the reproductive value of the brood $R_{\mathrm{AB}}\left(x_{\mathrm{M}}, x_{\mathrm{F}}, t\right)$ to have two components, the first of which represents the effects of care and parental reserves $r_{\mathrm{AB}}\left(x_{\mathrm{M}}, x_{\mathrm{F}}\right)$, while the second one corresponds to the seasonal effects $S(t)$ :

$$
R_{\mathrm{AB}}\left(x_{\mathrm{M}}, x_{\mathrm{F}}, t\right)=r_{\mathrm{AB}}\left(x_{\mathrm{M}}, x_{\mathrm{F}}\right) S(t)
$$

where $\mathrm{AB}$ specifies the pattern of care (see "The Model"), while $x_{\mathrm{M}}$ and $x_{\mathrm{F}}$ give the reserves of the caring male and female, respectively, at the end of the caring period. If a parent does not care, we set its reserves to zero in the above equation. This notation also allows us to incorporate easily the effect of the death of one or both parents occurring during care. The effect of care and parental reserves is modeled as follows.

If both parents desert, then the young certainly die:

$$
r_{\mathrm{DD}}(0,0)=0
$$

When only the male cares, the value of the offspring is

$$
r_{\mathrm{CD}}\left(x_{\mathrm{M}}, 0\right)=(1-h) V_{\mathrm{CD}}+\frac{h V_{\mathrm{CD}}}{L_{\mathrm{M}}} x_{\mathrm{M}} .
$$

Here, $h$ controls the effect of reserves on the young's value. If $h=0$, then the male's reserves do not affect the young's value, while if $h=1$, his reserves fully influence the offspring's value (hence offspring cared for only by a male with reserves close to zero have close to zero survival expectation). The maximal reserves with which a male can finish care are given by $L_{\mathrm{M}}=L-x_{c, M}(\mathrm{D})$. The value of care by a male with reserves $L_{\mathrm{M}}$ caring alone is given by $V_{\mathrm{CD}}$. The value 
of female-only care is similarly defined. If both parents care and both are alive at the end of the period of care, then the offspring's value is

$$
r_{\mathrm{CC}}\left(x_{\mathrm{M}}, x_{\mathrm{F}}\right)=\frac{1}{2}\left[a_{\mathrm{M}}\left(x_{\mathrm{F}}\right)+b_{\mathrm{M}}\left(x_{\mathrm{F}}\right) x_{\mathrm{M}}+a_{\mathrm{F}}\left(x_{\mathrm{M}}\right)+b_{\mathrm{F}}\left(x_{\mathrm{M}}\right) x_{\mathrm{F}}\right]
$$

where

$$
a_{\mathrm{M}}\left(x_{\mathrm{F}}\right)=h V_{\mathrm{DC}} \frac{x_{\mathrm{F}}}{L_{\mathrm{F}}}+(1-h) V_{\mathrm{CC}}
$$

and

$$
b_{\mathrm{M}}\left(x_{\mathrm{F}}\right)=\frac{h}{L_{\mathrm{M}}}\left[V_{\mathrm{CD}}+\left(V_{\mathrm{CC}}-V_{\mathrm{CD}}-V_{\mathrm{DC}}\right) \frac{x_{\mathrm{F}}}{L_{\mathrm{F}}}\right] \text {. }
$$

The values of $a_{\mathrm{F}}\left(x_{\mathrm{M}}\right)$ and $b_{\mathrm{F}}\left(x_{\mathrm{M}}\right)$ are defined by similar equations. In these equations, $h$ also controls the effect of reserves on the young's value. If $h=0$, then the parents' reserves do not affect the young's value, while if $h=1$, the parents' reserves fully influence the offspring's value. The maximal reserves with which a female can finish the care are given by $L_{\mathrm{F}}=L-x_{\mathrm{c}, \mathrm{F}}(\mathrm{C})$. The value of care by parents with maximum reserves $L_{\mathrm{M}}$ and $L_{\mathrm{F}}$ is $V_{\mathrm{CD}}, V_{\mathrm{DC}}$, and $V_{\mathrm{CC}}$ in the cases of male-only, female-only, and biparental care, respectively.

The function defined by equation (B4) has the following properties. It gives higher offspring value for biparental care unless $V_{\mathrm{CC}}=V_{\mathrm{CD}}=V_{\mathrm{DC}}$ and the reserves of the parent with higher $V$ has stronger effect on the young's value than those of with lower $V$.

The effect of time of the season on the offspring value is represented by the following function:

$$
S(t)= \begin{cases}\left(1+\left(1-\frac{\tau}{T}\right)^{\theta}\right)\left(\frac{(T-t)^{\theta}}{(T-t)^{\theta}+(T-\tau)^{\theta}}\right) & \text { when } 0 \leq t<T \\ 0 & \text { when } t \geq T .\end{cases}
$$

The shape of this time-dependent function is controlled by two parameters: $\theta$ gives the abruptness of the transition from high brood value to low brood value (the larger $\theta$ is, the more sudden the decrease), and $\tau$ is the time at which this transition occurs (Webb et al., in press). We use $\theta=2$ and $\tau=80$ in all of our computations.

\section{Solution of the Game}

To solve the dynamic parental care game, we use the "errors in decision making" approach (McNamara et al. 1997). Let $U_{\mathrm{M}}(x, t)$ be the reproductive value of an unmated male with reserves $x$ on day $t$. Let $W_{\mathrm{M}}(x, y, t)$ be the reproductive value of a mated male whose own reserves are $x$ and whose mate's reserves are $y$ on day $t$, just after finishing offspring production and about to decide on care. We assume that $U_{\mathrm{M}}(0, t), W_{\mathrm{M}}(0, y, t)=0$ (i.e., an animal with zero reserves dies) and that $W_{\mathrm{M}}(x, 0, t)=U_{\mathrm{M}}(x, t)$ (i.e., if the male's mate dies during the offspring production, then no surviving offspring are produced, and the male becomes unmated). We use

$$
E(x)=\frac{\exp (x / \delta)}{\exp (x / \delta)+1}
$$

as an error function with $\delta=0.015$ as the extent of error.

Decision of an Unmated Animal. In this section, we give the equations for an unmated male; analogous notation is used for unmated females. Let 


$$
\begin{gathered}
H_{\text {rest }, \mathrm{M}}(x, t)=\sum_{i=0}^{n} P_{i} U_{\mathrm{M}}\left\{\operatorname{chop}\left(x-x_{\mathrm{r}, \mathrm{M}}-z_{i}\right), t+1\right\}, \\
H_{\text {forage } \mathrm{M}}(x, t)=\sum_{i=0}^{n} P_{i} U_{\mathrm{M}}\left\{\operatorname{chop}\left(x+x_{\mathrm{f}}+z_{i}\right), t+1\right\},
\end{gathered}
$$

and

$$
H_{\text {search }, \mathrm{M}}(x, t)=\left[1-P_{\mathrm{M}}(t)\right] \sum_{i=0}^{n} P_{i} U_{\mathrm{M}}\left\{x^{\prime}, t+1\right\}+P_{\mathrm{M}}(t) \sum_{y=1}^{L} \sum_{i=0}^{n} \sum_{j=0}^{n} P_{\text {search, } \mathrm{F}}(y, t) P_{i} P_{j} W_{\mathrm{M}}\left\{x^{\prime \prime}, y^{\prime \prime}, t+t_{1}+1\right\}
$$

where $P_{\text {search, } \mathrm{F}}(y, t)$ is defined by equation (A1), $x^{\prime}=\operatorname{chop}\left(x-x_{\mathrm{s}, \mathrm{M}}-z_{i}\right), \quad x^{\prime \prime}=\operatorname{chop}\left(x-x_{1, \mathrm{M}}-z_{i}\right), \quad$ and $y^{\prime \prime}=$ $\operatorname{chop}\left(y-x_{1, \mathrm{~F}}-z_{j}\right)$.

Let $H_{\max , \mathrm{M}}(x, t)=\max _{a} H_{a, \mathrm{M}}(x, t)$, where $a$ is either "rest," "forage," or "search," and $\omega_{a, \mathrm{M}}(x, t)=E\left[H_{a, \mathrm{M}}(x, t)-\right.$ $\left.H_{\max , \mathrm{M}}(x, t)\right]$, where $E$ is given by equation (B8). Then

$$
\pi_{a, \mathrm{M}}(x, t)=\frac{\omega_{a, \mathrm{M}}(x, t)}{\sum_{a} \omega_{a, \mathrm{M}}(x, t)}
$$

gives the probability that the male with reserves $x$ on day $t$ performs action $a$. The value of $\pi_{a, M}(x, t)$ is also the best response with error (cf. McNamara et al. 1997) of an unmated male. Then the unmated male's reproductive value is

$$
U_{\mathrm{M}}(x, t)=\sum_{a} \pi_{a, \mathrm{M}}(x, t) H_{a, \mathrm{M}}(x, t)
$$

Decisions of a Mated Female. Assume that a pair has finished the production of offspring at time $t$ and that the male has decided whether or not to desert. Let $H_{\mathrm{AB}, \mathrm{M}}(x, y, t)$ be the payoff of the desertion game for the male making a decision at time $t$, while $H_{\mathrm{AB}, \mathrm{F}}(x, y, t)$ is the payoff for the female. The variables $x$ and $y$ denote the energy reserves of the focal animal and its partner, respectively. The caring decision of the pair is given by $\mathrm{AB}$ (see above). Let $t^{\prime}=t+t_{\mathrm{c}}+1$ throughout. If the male deserts, then the expected reproductive value of the female if she cares is

$$
H_{\mathrm{DC}, \mathrm{F}}(x, y, t)=\sum_{i=0}^{n} P_{i}\left\{R_{\mathrm{DC}}\left(0, x^{\prime}, t^{\prime}\right)+U_{\mathrm{F}}\left(x^{\prime}, t^{\prime}\right)\right\}
$$

where $x^{\prime}=\operatorname{chop}\left[x-x_{c, \mathrm{~F}}(\mathrm{D})-z_{i}\right]$. The reproductive value of a deserting female is

$$
H_{\mathrm{DD}, \mathrm{F}}(x, y, t)=\sum_{i=0}^{n} P_{i} U_{\mathrm{F}}\left\{\operatorname{chop}\left(x-x_{\mathrm{d}}-z_{i}\right), t+1\right\}
$$

because $R_{\mathrm{DD}}(x, y, t)=0$. Using the error function, we get that the probability of female desertion given that her male deserts is

$$
\pi_{\text {desert, } \mathrm{F}(\mathrm{D})}(x, y, t)=E\left[H_{\mathrm{DD}, \mathrm{F}}(x, y, t)-H_{\mathrm{DC}, \mathrm{F}}(x, y, t)\right]
$$

Similarly, if the male cares,

$$
H_{\mathrm{CC}, \mathrm{F}}(x, y, t)=\sum_{i=0}^{n} \sum_{j=0}^{n} P_{i} P_{j}\left\{R_{\mathrm{CC}}\left(y^{\prime}, x^{\prime}, t^{\prime}\right)+U_{\mathrm{F}}\left(x^{\prime}, t^{\prime}\right)\right\}
$$

where $x^{\prime}=\operatorname{chop}\left[x-x_{c, \mathrm{~F}}(\mathrm{C})-z_{i}\right]$, and $y^{\prime}=\operatorname{chop}\left[y-x_{c, M}(\mathrm{C})-z_{j}\right]$. If the male cares but the female deserts, 


$$
H_{\mathrm{CD}, \mathrm{F}}(x, y, t)=\sum_{i=0}^{n} \sum_{j=0}^{n} P_{i} P_{j}\left\{R_{\mathrm{CD}}\left(y^{\prime}, 0, t^{\prime}\right)+U_{\mathrm{F}}\left(x^{\prime}, t+1\right)\right\}
$$

where $x^{\prime}=\operatorname{chop}\left(x-x_{\mathrm{d}}-z_{i}\right)$, and $y^{\prime}=\operatorname{chop}\left[y-x_{c, M}(\mathrm{D})-z_{j}\right]$. The probability that the female deserts, given her mate cares, is then

$$
\pi_{\mathrm{desert}, \mathrm{F}(\mathrm{C})}(x, y, t)=E\left[H_{\mathrm{CD}, \mathrm{F}}(x, y, t)-H_{\mathrm{CC}, \mathrm{F}}(x, y, t)\right] .
$$

Similarly to the case of unmated individuals, $\pi_{\text {desert, } \mathrm{F}(A)}(x, y, t)$ also gives the best response of a mated female.

Decision of a Mated Male. Let the male decide on desertion at time $t$. As before, let $t^{\prime}=t+t_{\mathrm{c}}+1$. Then

$$
H_{\mathrm{CC}, \mathrm{M}}(x, y, t)=\sum_{i=0}^{n} \sum_{j=0}^{n} P_{i} P_{j}\left\{R_{\mathrm{CC}}\left(x^{\prime}, y^{\prime}, t^{\prime}\right)+U_{\mathrm{M}}\left(x^{\prime}, t^{\prime}\right)\right\},
$$

where $x^{\prime}=\operatorname{chop}\left[x-x_{c, \mathrm{M}}(\mathrm{C})-z_{i}\right], y^{\prime}=\operatorname{chop}\left[y-x_{c, \mathrm{~F}}(\mathrm{C})-z_{j}\right]$

$$
H_{\mathrm{CD}, \mathrm{M}}(x, y, t)=\sum_{i=0}^{n} P_{i}\left\{R_{\mathrm{CD}}\left(x^{\prime}, 0, t^{\prime}\right)+U_{\mathrm{M}}\left(x^{\prime}, t^{\prime}\right)\right\}
$$

where $x^{\prime}=\operatorname{chop}\left[x-x_{c, M}(\mathrm{D})-z_{i}\right]$

$$
H_{\mathrm{DC}, \mathrm{M}}(x, y, t)=\sum_{i=0}^{n} \sum_{j=0}^{n} P_{i} P_{j}\left\{R_{\mathrm{DC}}\left(0, y^{\prime}, t^{\prime}\right)+U_{\mathrm{M}}\left(x^{\prime}, t+1\right)\right\},
$$

where $x^{\prime}=\operatorname{chop}\left(x-x_{\mathrm{d}}-z_{i}\right)$, and $y^{\prime}=\operatorname{chop}\left[y-x_{\mathrm{c}, \mathrm{F}}(\mathrm{D})-z_{j}\right]$; and

$$
H_{\mathrm{DD}, \mathrm{M}}(x, y, t)=\sum_{i=0}^{n} P_{i} U_{\mathrm{M}}\left\{\operatorname{chop}\left(x-x_{\mathrm{d}}-z_{i}\right), t+1\right\}
$$

Let $\beta_{\mathrm{F}}(\mathrm{C})=\pi_{\mathrm{desert}, \mathrm{F}(\mathrm{C})}(x, y, t)$ and $\beta_{\mathrm{F}}(\mathrm{D})=\pi_{\mathrm{desert}, \mathrm{F}(\mathrm{D})}(x, y, t)$, then the expected reproductive value for the male if he cares is

$$
W_{\mathrm{M}}(\mathrm{C})=\left[1-\beta_{\mathrm{F}}(\mathrm{C})\right] H_{\mathrm{CC}, \mathrm{M}}(x, y, t)+\beta_{\mathrm{F}}(\mathrm{C}) H_{\mathrm{CD}, \mathrm{M}}(x, y, t),
$$

and the expected reproductive value if he deserts is

$$
W_{\mathrm{M}}(\mathrm{D})=\left[1-\beta_{\mathrm{F}}(\mathrm{D})\right] H_{\mathrm{DC}, \mathrm{M}}(x, y, t)+\beta_{\mathrm{F}}(\mathrm{D}) H_{\mathrm{DD}, \mathrm{M}}(x, y, t) .
$$

Thus, the male deserts with probability

$$
\beta_{\mathrm{M}}=\pi_{\mathrm{desert}, \mathrm{M}}(x, y, t)=E\left[W_{\mathrm{M}}(\mathrm{D})-W_{\mathrm{M}}(\mathrm{C})\right],
$$

which also gives his best response with error.

Payoff of the Desertion Game. Given the above reproductive values and probabilities, the expected reproductive value of a paired male on finishing offspring production at time $t$ is

$$
W_{\mathrm{M}}(x, y, t)=\left(1-\beta_{\mathrm{M}}\right) W_{\mathrm{M}}(\mathrm{C})+\beta_{\mathrm{M}} W_{\mathrm{M}}(\mathrm{D}),
$$

whereas for a female on the same occasion it is 


$$
\begin{aligned}
W_{\mathrm{F}}(x, y, t)= & \left(1-\beta_{\mathrm{M}}\right)\left\{\left[1-\beta_{\mathrm{F}}(\mathrm{C})\right] H_{\mathrm{CC}, \mathrm{F}}(x, y, t)+\beta_{\mathrm{F}}(\mathrm{C}) H_{\mathrm{CD}, \mathrm{F}}(x, y, t)\right\} \\
& +\beta_{\mathrm{M}}\left\{\left[1-\beta_{\mathrm{F}}(\mathrm{D})\right] H_{\mathrm{DC}, \mathrm{F}}(x, y, t)+\beta_{\mathrm{F}}(\mathrm{D}) H_{\mathrm{DD}, \mathrm{F}}(x, y, t)\right\} .
\end{aligned}
$$

The above equations are solved by working backward from the final time when

$$
U_{\mathrm{M}}(x, T)=R_{T}(x),
$$

where $R_{T}(x)$ may represent the dependence of overwinter survival on energy reserves at the beginning of the winter. We assume $R_{T}(x)$ will be the same for both sexes. In the computations, $R_{T}(x)$ was represented by a threshold function

$$
R_{T}(x)= \begin{cases}1 & \text { if } x>x_{L} \\ 0 & \text { if } x \leq x_{L}\end{cases}
$$

where $x_{L}=0$.

\section{Literature Cited}

Alonzo, S. H., and R. R. Warner. 2000. Female choice, conflict between the sexes and the evolution of male alternative reproductive behaviours. Evolutionary Ecology Research 2:149-170.

Balshine-Earn, S., and D. J. D. Earn. 1998. On the evolutionary pathway of parental care in cichlid fishes. Proceedings of the Royal Society of London B, Biological Sciences 265:2217-2222.

Bart, J., and A. Tornes. 1989. Importance of monogamous male birds in determining reproductive successevidence for house wrens and a review of male-removal studies. Behavioral Ecology and Sociobiology 24:109-116.

Clark, C. W., and M. Mangel. 2000. Dynamic state variable models in ecology. Oxford University Press, New York.

Clutton-Brock, T. H. 1991. The evolution of parental care. Princeton University Press, Princeton, N.J.

Cuthill, I. C., and A. I. Houston. 1997. Managing time and energy. Pages 97-120 in J. R. Krebs and N. B. Davies, eds. Behavioural ecology: an evolutionary approach. 4 th ed. Blackwell Science, Oxford.

Daan, S., C. Dijkstra, R. Drent, and T. Meijer. 1989. Food supply and the annual timing of avian reproduction. Pages 392-407 in H. Oullet, ed. Acta XIX international congress of ornithology. University of Ottawa Press, Ottawa.

Dawkins, R., and T. R. Carlisle. 1976. Parental investment, mate desertion and a fallacy. Nature 262:131-133.

Emlen, S. T., and L. W. Oring. 1977. Ecology, sexual selection and the evolution of mating systems. Science (Washington, D.C.) 197:215-223.

Freed, L. A. 1981. Loss of mass in breeding wrens: stress or adaptation? Ecology 62:1179-1186.

Golet, G. H., and D. B. Irons. 1999. Raising young reduces body condition and fat stores in black-legged kittiwakes. Oecologia (Berlin) 120:530-538.

Hammerstein, P., and G. A. Parker. 1987. Sexual selection: games between the sexes. Pages 119-142 in J. W. Bradbury and M. B. Andersson, eds. Sexual selection: testing the alternatives. Wiley, New York.

Hillström, L. 1995. Body mass reduction during reproduction in the pied flycatcher Ficedula hypoleuca: physiological stress or adaptation for lowered cost of locomotion? Functional Ecology 9:807-817.

Hõrak, P., S. Jenni-Eiermann, and I. Ots. 1999. Do great tits (Parus major) starve to reproduce? Oecologia (Berlin) 119:293-299.

Houston, A. I. 1993. The efficiency of mass-loss in breeding birds. Proceedings of the Royal Society of London B, Biological Sciences 254:221-225.

Houston, A. I., and J. M. McNamara. 1999. Models of adaptive behaviour. Cambridge University Press, Cambridge.

Houston, A. I., J. M. McNamara, C. W. Clark, and M. Mangel. 1988. Dynamic models in behavioural and evolutionary ecology. Nature 332:29-34.

Keenleyside, M. H. A. 1983. Mate desertion in relation to adult sex ratio in the biparental cichlid fish Herotilapia multispinosa. Animal Behaviour 31:683-688.

Kelly, E. J., and P. L. Kennedy. 1993. A dynamic state variable model of mate desertion in Cooper's hawks. Ecology 74:351-366.

Lack, D. 1968. Ecological adaptations for breeding in birds. Chapman \& Hall, London.

Liker, A. 1995. Monogamy in precocial birds: a review. Ornis Hungarica 5:1-14.

Mangel, M., and C. W. Clark. 1988. Dynamic modeling in behavioral ecology. Princeton University Press, Princeton, N.J. 
Maynard Smith, J. 1977. Parental investment: a prospective analysis. Animal Behaviour 25:1-9.

1982. Evolution and the theory of games. Cambridge University Press, Cambridge.

McNamara, J. M., J. N. Webb, E. J. Collins, T. Székely, and A. I. Houston. 1997. A general technique for computing evolutionarily stable strategies based on errors in decision-making. Journal of Theoretical Biology 189: 211-225.

McNamara, J. M., T. Székely, J. N. Webb, and A. I. Houston. 2000. A dynamic game-theoretic model of parental care. Journal of Theoretical Biology 205:605-623.

Moreno, J. 1989. Strategies of mass change in breeding birds. Biological Journal of the Linnean Society 37: 297-310.

Norberg, R. Å. 1981. Temporary weight decrease in breeding birds may result in more fledged young. American Naturalist 118:838-850.

Nur, N. 1984. The consequences of brood size for breeding blue tits. 1. Adult survival, weight change and the cost of reproduction. Journal of Animal Ecology 53:479-496.

Olsson, O. 1997. Clutch abandonment: a state-dependent decision in King penguins. Journal of Avian Biology 28: 264-267.

Pilastro, A., L. Biddau, G. Marin, and T. Mingozzi. 2001. Female brood desertion increases with number of available mates in rock sparrow. Journal of Avian Biology 32:68-72.

Ricklefs, R. E. 1974. Energetics of reproduction in birds. Pages 152-297 in R. A. Paynter, Jr., ed. Avian energetics. Publications of the Nuttall Ornithological Club, no. 15. Cambridge, Mass.

Selten, R. 1980. A note on evolutionarily stable strategies in asymmetric animal conflicts. Journal of Theoretical Biology 84:93-101.

Snyder, N. F. R., S. R. Beissinger, and R. E. Chandler. 1989. Reproduction and demography of the Florida Everglade (snail) kite. Condor 91:300-316.
Stearns, S. C. 1992. The evolution of life histories. Oxford University Press, Oxford.

Székely, T., and I. C. Cuthill. 1999. Brood desertion in Kentish plover: the value of parental care. Behavioral Ecology 10:191-197.

Székely, T., J. N. Webb, A. I. Houston, and J. M. McNamara. 1996. An evolutionary approach to offspring desertion in birds. Pages 271-330 in V. Nolan, Jr., and E. D. Ketterson, eds. Current ornithology. Vol. 13. Plenum, New York.

Temrin, H., and B. S. Tullberg. 1995. A phylogenetic analysis of the evolution of avian mating systems in relation to altricial and precocial young. Behavioral Ecology 6: 296-307.

Thomas, V. G. 1989. Body condition, ovarian hierarchies, and their relation to egg formation in anseriform and galliform species. Pages 353-363 in H. Oullet, ed. Acta XIX international congress of ornithology. University of Ottawa Press, Ottawa.

Webb, J. N., A. I. Houston, J. M. McNamara, and T. Székely. 1999. Multiple patterns of parental care. Animal Behaviour 58:983-993.

Webb, J. N., T. Székely, A. I. Houston, and J. M. McNamara. In press. A theoretical analysis of the energetic cost and consequences of parental care decisions. Philosophical Transactions of the Royal Society of London B, Biological Sciences.

Witter, M. S., and I. C. Cuthill. 1993. The ecological costs of avian fat storage. Philosophical Transactions of the Royal Society of London B, Biological Sciences 340: 73-92.

Wolf, L., E. D. Ketterson, and V. Nolan, Jr. 1990. Behavioural response of female dark-eyed juncos to the experimental removal of their mates-implications for the evolution of male parental care. Animal Behaviour 39: $125-134$. 